\title{
Development of a Routines-Based \\ Early Childhood Intervention model
}

\section{Desenvolvimento de um modelo de Intervenção Baseado em Rotinas da Primeira Infância}

\author{
Carolyn H. Hughes-Scholes ${ }^{1}$ \\ Susana Gavidia-Payne ${ }^{1}$
}

\begin{abstract}
The Early Childhood Intervention (ECI) literature recommends that intervention is embedded within everyday routines that occur in the natural environment. However, little research has examined the implementation of routines-based models of ECI. The aim of this paper was to describe the development of a Routines-Based Early Childhood Intervention (RBECI) model. The RBECI model consists of four key components: a) RoutinesBased Interviews (RBIs); b) participation-based goals; c) home visits; and d) community consultations. Empirical evidence supporting each component of the model is provided, and results from a preliminary evaluation of the implementation of the model are discussed. Further research is required evaluating processes involved in the implementation of the model by ECI professionals and its impact on children and families.
\end{abstract}

Keywords: early childhood intervention; routines-based intervention; evidence-based strategies.

\section{RESUMO}

A literatura recomenda que a Intervenção Precoce na Infância (IPI) seja inserida dentro das rotinas diárias que ocorrem no ambiente natural. No entanto, poucas pesquisas examinaram a implementação de modelos de IPI

DOI: $10.1590 / 0104-4060.44616$

1 Royal Melbourne Institute of Technology (RMIT) University. Melbourne, Australia. P.O. Box 71, Bundoora, VIC 3083.E-mails: carolyn.hughes-scholes@rmit.edu.au; susana-gavidia-payne@ rmit.edu.au 
com base em rotinas. O objetivo deste trabalho foi descrever o desenvolvimento de uma intervenção precoce na infância baseado num modelo de rotinas (RBECI). O modelo RBECI consiste em quatro componentes principais: a) Entrevistas Baseadas em Rotinas (RBI); b) metas de participação; c) visitas domiciliares; e d) consultas à comunidade. Evidência empírica de suporte para cada componente do modelo é fornecida, e os resultados de uma avaliação preliminar da implementação do modelo são discutidos. São necessárias mais pesquisas e avaliações dos processos envolvidos na implementação do modelo por profissionais de IPI e seu impacto sobre as crianças e as famílias.

Palavras-chave: intervenção precoce na infância; intervenção baseada em rotinas; estratégias baseadas em evidências.

In Australia, 22\% of children are developmentally vulnerable on one or more domains including; physical health and well-being, social competence, emotional maturity, language and cognition prior to entering school (Australian Centre for Community Child Health, 2012). During early childhood (birth to 6 years of age), children with a developmental delay ${ }^{2}$ or disability and their families can access specialised supports and services through early childhood intervention (ECI) programs. (SUKKAR, 2013). These programs aim to promote children's development, well-being and community participation and may involve a variety of components, including coordination of services, home visiting, collaborative consultation to caregivers within community settings such as child care providers or preschool teachers, small group interventions, and parent support groups. In Australia, ECI programs are generally delivered in a transdisciplinary manner, whereby one ECI professional (referred to as a Key Worker) is allocated to collaborate with an individual family and provide information, support and resources during regular home visits and community consultations. (MCWILLIAM, 2010; SUKKAR, 2013). Each Key Worker receives support from a team of professionals who come from a variety of disciplines, such as allied health and special education, and are available to provide additional services to the family if needed. Like elsewhere in the world, the ECI field in Australia recommends that intervention is embedded within everyday routines that occur in the natural environment (SUKKAR, 2013), therefore promoting the inclusion of children in everyday settings. Little research, however, has been conducted that examines the implementation of routines-based models of ECI. Thus, the aims of the current paper are threefold: 1) to outline the rationale for routines-based disabilities.

2 This term will be used broadly to include children with a range of developmental 
intervention as the basis for including children with developmental delays in everyday life; 2) discuss the empirical evidence supporting components of a routines-based early childhood intervention model; and 3) describe results from a preliminary evaluation of the implementation of the model.

\section{Inclusion of Young Children with Developmental Delays}

It is a recommended practice in ECI for children with developmental delays or disabilities to access and participate in mainstream early childhood education and care (ECEC) programs (i.e., child care, preschool). The inclusion of children with disabilities in regular settings provides them with a developmentally stimulating learning environment whereby they have the opportunity to learn the skills necessary to successfully participate in these settings. (ODOM; WOLERY, 2003). Research has reported a number of benefits of inclusion for preschool children with disabilities, including increased positive behaviours and social interaction compared to children in segregated settings. Furthermore, typically developing children have also been shown to benefit from inclusive settings, including greater knowledge about, and understanding of disabilities. Finally, families are mostly positive about their children participating in inclusive settings and they become more positive over time. (ODOM et al., 2004). However, for children and families to benefit from inclusion, it is important that the ECEC programs are of a high quality, adapted to take into consideration the additional needs of children, in which support is provided to ensure effective inclusion (e.g., professional development, continuing coaching and consultation, planning time), collaboration among ECI professionals and ECEC professionals is ongoing, parents are collaborated with to determine their priorities for their children, and that intervention is embedded into identified activities or routines that occur in the natural environment. (ODOM et al., 2004; ODOM; BUYSSE; SOUKAKOU, 2011).

\section{Routines-Based Intervention}

Central to the routines-based approach to intervention is the premise that children learn best in the contexts (that is, daily routines) provided by their 
families and other caregivers. (DUNST et al., 2006). Routines are defined as naturally occurring activities that happen with some degree of regularity (e.g., getting dressed, mealtimes). (MCWILLIAM, 2010). Everyday routines provide an optimal context for young children to acquire and refine skills, because they are repetitive, predictable, functional and meaningful. (CHESLOCK; KAHN, 2011). Furthermore, the regularity in which routines occur over extended time periods enable the child to learn the consequences of his or her behaviour. (BRONFENBRENNER, 1999). Unlike traditional one-on-one therapy, embedding intervention within routines encourages the generalisation and maintenance of skills into other activities. (BRUDER, 2010).

Families are viewed as central to early intervention efforts that use daily activities and routines as contexts for learning. The role of the family is to promote their child's development through the provision of learning opportunities in everyday activities. (DUNST, 2002; MCWILLIAM, 2010). ECI professionals only have limited contact hours with the child, therefore parents or caregivers have the greatest opportunity to enhance their child's development. (BRUDER, 2010). The role of ECI professionals is to work collaboratively with families and use coaching techniques to develop parent's skills, knowledge, competencies and confidence to be able to provide development enhancing learning opportunities. (RUSH; SHELDEN; HANFT, 2003).

While many ECI programs embed intervention into the everyday lives and routines of families, little research has been conducted that explores the implementation of routines-based intervention. We recently developed a routines-based early childhood intervention model (RBECI) based on Robin McWilliam's routines-based early intervention model. (see MCWILLIAM, 2010). This model focuses on embedding learning opportunities into family's daily routines to achieve functional outcomes, namely children's engagement, independence, social relationships, and family satisfaction with routines, which ultimately improve child and family functioning. The model focuses on early childhood, i.e., birth to 6 years, and occurs within a transdisciplinary Key Worker framework. It consists of four key components: (a) Routines-Based Interviews (RBIs); (b) participation-based goals; (c) home visits; and (d) community consultations. Although these components are widely accepted within ECI as 'good practice', they have varying levels of empirical evidence supporting their use. Each component of the model and the empirical evidence behind them will be discussed in turn. 


\section{Routines-based interviews}

The implementation of the model begins with a RBI, which is a semistructured interview conducted by an ECI professional with the family in their home (or child care provider if a child is in care for more than 15 hours per week) that takes up to $2 \mathrm{hrs}$. The aim of the RBI is to elicit information about a child and family's daily routines in order to develop functional child and family participation-based goals, to assess child and family functioning, and establish a positive relationship with the family. (MCWILLIAM, 2010; MCWILLIAM; CASEY; SIMS, 2009). For each typical daily routine, the family is asked questions regarding what each family member does during the routine; the child's participation in the routine in terms of their engagement, social relationships, and independence; the family's satisfaction with the routines; and the family's major concerns and priorities. The families' priorities become the participation-based goals on the individual family service plan (IFSP) and form the framework for intervention. (MCWILLIAM, 2010).

\section{Participation-based goals}

Quality goals are important for informing professionals, families and other caregivers when, where, and how intervention is to take place, monitoring progress, and evaluating the effectiveness of an intervention. (MCWILLIAM et al., 1998). Researchers have outlined criteria that goals must meet to be considered high quality goals: they should reflect the priorities, beliefs and values of the family; address functional skills that facilitate the child's and family's participation in their natural environments, that is, the home and community; be measurable and generalisable, so that the achievement of a specific skill is recognised; and be written in such a way that they are understandable to families. (JUNG; BAIRD, 2003; JUNG; MCWILLIAM, 2005; MCWILLIAM, 2010). However, research has shown that often goals do not meet these recommended criteria. Instead, goals are neither functional nor meaningful, failing to consider natural environments. (MCWILLIAM et al., 1998). Further, goals are frequently focused on the child rather than the whole family (BOONE et al., 1998), lack a degree of specificity and measurable criteria for knowing when the outcome has been achieved. (MCWILLIAM et al., 1998). These findings highlight that 
the quality of participation-based goals on IFSPs requires improvement. This is particularly important as poor quality goals may lead to ineffective interventions for children and their families.

Recently research has been conducted to examine whether implementing an RBI improves the functionality of participation-based goals on the IFSP. In a preliminary study by McWilliam and colleagues (2009), 16 families received either the RBI prior to the development of the IFSP or the standard IFSP development process whereby no RBI was conducted. The results revealed that families who received the RBI reported greater satisfaction with the IFSP development process compared to families who participated in the standard IFSP development process, and the latter families had more variable responses. A greater number of participation-based goals, and more functional goals were produced when the RBI was implemented compared to the standard IFSP development process. Similarly, Boavida, Aguiar and McWilliam (2014) found that the quality of participation-based goals and objectives on IFSPs written by 80 professionals increased by over three standard deviations after they participated in training that focused on conducting RBIs. Further support for the RBI was provided in a quasiexperimental study by Boavida et al. (2015), whereby the quality of goals produced by 36 professionals who attended an in-service training program on the RBI was significantly higher than a control group 1 year after the training. These studies provide initial support for use of the RBI in assisting ECI professionals to develop functional participation-based goals on IFSPs. However, further research needs to be conducted to replicate findings to enlarge the evidence base for the RBI.

\section{Home visits}

Once participation-based goals have been developed, the third component of the model involves ECI professionals working with the family to achieve these goals during home visits. One of the benefits of home visits compared to traditional centre-based visits is that the ECI professionals can capitalise on the natural learning environments in the home. (BRUDER, 2010). New intervention strategies learned by the family can be easily implemented into the activity setting where they are intended to be used, rather than transferred back at a later date. (BRUDER, 2010; PETERSON et al., 2007). It is recommended that ECI professionals' use coaching strategies during home visits, such as observing, listening, modelling, reflection, performance feedback, and problem solving, 
which are designed to enhance positive family and child interactions and learning opportunities. (RUSH; SHELDEN; HANFT, 2003). When coaching strategies are implemented with fidelity, a triadic interaction will ensue (ECI professionalchild-families), whereby the ECI professional regularly meets with the child's family to enhance their competence and confidence to implement effective practices that support the child's development within naturally occurring routines and activities. (RUSH; SHELDEN; HANFT, 2003; SHELDEN; RUSH, 2010). However, there is evidence to show that ECI professionals are not consistently implementing coaching strategies during home visits. Specifically, studies have demonstrated that ECI professionals spend the majority of their time (51-83\%) interacting directly with the child (e.g., HEBBELER et al., 2008; PETERSON et al., 2007), while the family simply observes the session with no opportunity to interact with their child and practice the skills being modelled. (PETERSON et al., 2007). Further, ECI professionals spend little to no time explicitly coaching the family. (e.g., PETERSON et al., 2007). However, recent research (SALISBURY; CAMBRAY-ENGSTROM; WOODS, 2012; SALISBURY; WOODS; COPELAND, 2010) has revealed that ECI professionals will utilise a range of coaching practices throughout home visits when ongoing support is provided. In addition, they report feeling more confident adopting and implementing coaching practices and less concerned about conducting home visits after receiving training, reflective practice, and problem solving regarding implementation issues.

Only one study to date has examined the effectiveness of home visiting within a routines-based model compared to traditional home visiting (THV). Hwang, Choa, and Liu (2013) conducted a randomised control study with 31 families of children aged between 5 and 30 months with or at risk for developmental delay. Half of the families received the routines-based early intervention (RBEI) for 6-months which involved a home visitor conducting an RBI, coaching and collaborating with families to identify functional child goals and design intervention strategies that were embedded within their everyday routines. The remaining families received the THV, whereby a home visitor used a curriculumbased developmental evaluation to assess the child's abilities, instructed families to set developmental goals, and chose intervention strategies for the families to use without a focus on routines. For both groups, the children's outcomes were measured at five time points and goal achievements were measured at two time points. Results revealed that the RBEI was more effective than TVH in promoting children's functional outcomes and attaining family-selected child goals within the first 3 months of intervention and at the 6-month follow-up. However, there was no significant difference between intervention groups in developmental domains. Although this study provides initial support for home visiting conducted within routines-based intervention, it did not investigate goals 
and outcomes related to the family and families did not receive intervention in community-based settings.

\section{Community consultations}

In addition to ECI professionals conducting home visits, the RBECI model also includes collaborative consultation to caregivers within community settings, such as child care providers or preschool teachers. ECI professionals provide professional support to caregivers with the aim of promoting their ability to support the needs of children under their care. (JAYARAMAN et al., 2015). It is recommended that ECI professionals utilise coaching strategies when conducting community consultations. (RUSH; SHELDEN; HANFT, 2003). Although research has provided evidence for the use of coaching practices in ECI (e.g., FOX et al., 2011; KNOCHE et al., 2012), relatively little research has examined ECI professionals' coaching of caregivers in community-based settings. A recent study by Jayaraman et al. (2015) that examined coaching conversations between ECI professionals and preschool teachers and child care providers, revealed that there is much variability in the use of recommended coaching strategies by ECI professionals. ECI professionals spent a minimal amount of time inviting questions that promote reflection, sharing observations, and engaging in joint planning, which are considered important practices to enable both professionals and teachers to stay engaged and collaborate to achieve mutually-agreed upon goals. However, they frequently used verbal and nonverbal acknowledgements and shared information with the teachers. Further, Knoche, Kuhn, and Eum (2013) examined the perceptions of coaches (i.e., preschool teachers, child care providers and parents) related to their coaching experiences with ECI professionals. They reported improvements in their daily practice related to their knowledge of child development, ability to promote children's development, and preparation for working as a member of a team as a result of interacting with their coach. Further, they reported affective changes, including more open-mindedness, commitment, persistence and self-image. While these studies have highlighted some of the strengths and limitations of collaborative consultation in community settings, they were not conducted in the context of a routines-based intervention approach. 


\section{Evaluation of the RBECI model}

We recently conducted the first study to provide a preliminary evaluation of the implementation of the RBECI model of practice as a whole by Australian ECI practitioners (HUGHES-SCHOLES et al., 2015). Five ECI professionals and nine families from an Australian ECI service participated in the study. Professionals' knowledge, understanding, confidence, home visiting and community consultation skills were assessed immediately before and 6 months after receiving training in the model. The quality of the RBIs and participation-based goals produced during the intervention were also assessed. Finally, individual in-depth interviews elicited professionals' perspectives on implementing the model. The results revealed that professionals' knowledge, understanding, confidence, and home visiting skills increased from pre- to post-intervention, but community consultation skills did not. There were limitations in the quality of RBIs and participation-based goals produced. Specifically, when professionals implemented the RBIs, they omitted or frequently omitted questions about the child's social relationships, the child's functioning, and what parents would like to see next in the routines when there were no problems. While functional participationbased goals were developed by professionals, a meaningful acquisition criterion and a generalisation criterion was frequently omitted from the goals. Overall, professionals were positive about the implementation of the model. Specifically, they reported that the RBIs elicited a broader range of information which enabled them to produce more functional participation-based goals compared to previously used assessment tools. Further, professionals were positive about the impact that embedding intervention within routines had on home visits and community consultations. However, professionals felt pressure from parents to commence intervention prior to completing the RBI, because families were frustrated with the length of time it was taking to complete the initial paperwork associated with the RBECI model. This study provided preliminary support for the RBECI model as a whole to be implemented in ECI more broadly. However, the study highlighted the need for professionals to receive additional training, coaching and supervision to improve their ability to effectively implement the RBECI model, especially in terms of community consultation skills.

We were also interested in examining the impact of the RBECI implementation on children's participation in routines at home and in the community (i.e., child care and preschool). Seven of the nine families who participated in the study outlined above took part. Of their children receiving services, 2 were males and 5 were females aged between 27 and 49 months 
$(M=40.71, S D=7.39)$. Children's behaviour was assessed pre and 6 months post implementation of the RBECI model of practice. Specifically, children's behaviour was observed in the home for 10 minutes during a routine that the family had prioritised (e.g., mealtime, getting dressed), and at childcare or preschool for 10 minutes during 'free play'. The children's behaviour was rated using the Adapted Vanderbilt Ecological Congruence of Teaching (VECTOR) (CASEY; FREUND; MCWILLIAM, 2004) which measures the opportunities families provide in the home and ECEC professionals provide in the community setting and the extent to which children take advantage of the opportunities. The results revealed that while there was no significant improvement in opportunities provided within the home or childcare/preschool pre- to post-intervention, there was a significant improvement in the extent to which children were taking advantage of opportunities in home and childcare/preschool. As can be seen in Table 1, there was an improvement in children using the physical environment and available materials to be consistently engaged in the home and childcare/ preschool, an improvement in children completing home and classroom routines independently and an improvement in parent-child interaction in the home. However, there was no improvement in peer interaction in childcare/ preschool from pre- to post-implementation of the RBECI model. Overall, this study provided preliminary evidence that the implementation of the RBECI components improved children's participation in their daily routines at home and in the community.

\section{Conclusion}

It is concluded that the implementation of routines-based intervention models is critical to improve the functioning of children with developmental delays and their families in mainstream settings, due to increased engagement, independence and social relationships in children and families' satisfaction with daily routines. The current paper provided preliminary evidence supporting the implementation of various components of a routines-based model of ECI, including RBIs, participation-based goals, and home visits. Further research is needed to improve the implementation of community consultations. In addition, more research is required evaluating processes involved in the implementation of such a model by ECI professionals and its impact on children and families. The routines-based approach to ECI has the potential to facilitate system-wide 
change in the way intervention is delivered, thus it is imperative that the popularity of the approach is supported by empirical evidence that demonstrates links between specific practices and child and family outcomes.

TABLE 1 - CHILDREN TAKING ADVANTAGE OF TEACHING AND LEARNING OPPORTUNITIES IN THE HOME AND COMMUNITY

\begin{tabular}{|c|c|c|c|c|c|c|}
\hline & \multicolumn{2}{|c|}{ Pre-Intervention } & \multicolumn{2}{|c|}{ Post-Intervention } & \multirow[b]{2}{*}{$t$} & \multirow[b]{2}{*}{$p$} \\
\hline & $M$ & $S D$ & $M$ & $S D$ & & \\
\hline \multicolumn{7}{|l|}{ Home } \\
\hline $\begin{array}{l}\text { Child uses the physical home } \\
\text { environment and available materials }\end{array}$ & & & & & & \\
\hline to be consistently engaged & 3.00 & 1.26 & 4.67 & 0.82 & -5.00 & .004 \\
\hline $\begin{array}{l}\text { Child completes home routines } \\
\text { independently }\end{array}$ & 2.17 & 1.17 & 3.83 & .75 & -5.00 & .004 \\
\hline $\begin{array}{l}\text { Child interacts frequently and } \\
\text { appropriately with parents }\end{array}$ & 3.17 & 1.47 & 4.67 & .52 & -2.67 & .045 \\
\hline \multicolumn{7}{|l|}{ Community } \\
\hline $\begin{array}{l}\text { Child uses the physical environment } \\
\text { and available materials to be }\end{array}$ & & & & & & \\
\hline consistently engaged & 2.57 & .79 & 3.42 & .79 & -3.29 & .02 \\
\hline $\begin{array}{l}\text { Child completes classroom routines } \\
\text { independently }\end{array}$ & 2.57 & .98 & 3.57 & .53 & -4.58 & .04 \\
\hline $\begin{array}{l}\text { Child interacts frequently and } \\
\text { appropriately with peers }\end{array}$ & 1.71 & .76 & 2.14 & .69 & -1.00 & .36 \\
\hline
\end{tabular}

\section{REFERENCES}

AUSTRALIAN CENTRE FOR COMMUNITY CHILD HEALTH. A snapshot of early childhood development in Australia: AEDI National Report 2012. Available at: $<$ https:// www.aedc.gov.au/.../reports/report_nationalreport_2012.pdf>. Access: Dec. 2015.

BOAVIDA, T.; AGUIAR, C.; MCWILLIAM, R. A training program to improve IFSP/ IEP goals and objectives though the Routines-Based Interview. Topics in Early Childhood Special Education, v. 33, n. 4, p. 200-211, 2014.

BOAVIDA, T. et al. Effects of using an in-service training program using the RoutinesBased Interview. Topics in Early Childhood Special Education. Advance online publication, 14 Sept. 2015. 
BOONE, H. A. et al. IFSP practices in two states: Implications for practice. Infants and Young Children, v. 10, n. 4, p. 36-45, 1998.

BRONFENBRENNER, U. Environments in developmental perspective: Theoretical and operational models. In: FRIEDMAN, S. L.; WACHS, T. D. (Eds.). Measuring environment across the life span: emerging methods and concepts. Washington: American Psychological Association, 1999, p. 3-28.

BRUDER, M. B. Early childhood intervention: A promise to children and families for their future. Exceptional Children, v. 76, n. 3, p. 339-355, 2010.

CASEY, A. M.; FREUND, P. J.; MCWILLIAM, R. A. Vanderbilt Ecological Congruence of Teaching Opportunities in Routines (VECTOR) - Classroom Version. Bashville: Vanderbilt Center for Child Development, 2004.

CHESLOCK, M. A.; KAHN, S. J. Supporting families and caregivers in everyday routines. ASHA Leader, v. 16, p. 10-13, 2011.

DUNST, C. J. Family-centered practices: Birth through high school. The Journal of Special Education, v. 36, n. 3, p. 139-147, 2002.

DUNST, C. J. et al. Everyday activity settings, natural learning environments and early intervention practices. Journal of Policy and Practice in Intellectual Disabilities, v. 3, n. 1, p. 3-10, 2006.

FOX, L. et al. Coaching early childhood special educators to implement a comprehensive model for promoting young children's social emotional competence. Topics in Early Childhood Special Education, v. 31, n. 3, p. 178-192, 2011.

HEBBELER, K. et al. A national look at the characteristics of Part C early intervention services. In: PETERSON, C. A.; FOX, L.; BLASCO, P. M. (Eds.). Early intervention for infants and toddlers and their families: Practices and outcomes [Young Exceptional Children Monograph 10]. Missoula: Division for Early Childhood, 2008. p. 1-18.

HUGHES-SCHOLES, C. H. et al. Preliminary evaluation of a Routines-Based Early Childhood Intervention model: Practitioners' Perspectives. Topics in Early Childhood Special Education. Advance online publication, 23 Jun. 2015.

HWANG, A. W.; CHOA, M. Y.; LIU, S. W. A randomised controlled trial of routines-based early intervention for children with or at risk for developmental delay. Research in Developmental Disabilities, v. 34, n. 10, p. 3112-3123, Oct. 2013.

JAYARAMAN, G. et al. Coaching conversations in early childhood programs: The contributions of coach and coachee. Infants \& Young Children, v. 28, n. 4. p. 323-336, 2015.

JUNG, L. A.; BAIRD, S. M. Effects of service coordinator variables on individualized family service plans. Journal of Early Intervention, v. 25, n. 3, p. 206-218, Jan. 2003.

JUNG, L. A.; MCWILLIAM, R. A. Reliability and validity of scores on the IFSP rating scale. Journal of Early Intervention, v. 27, n. 2, p. 125-136, 2005. 
KNOCHE, L. L.; KUHN, M; EUM, J. More time. More showing. More helping. That's how it sticks: The perspectives of early childhood coachees. Infants \& Young Children, v. 26, n. 4, p. 349-365, 2013.

KNOCHE, L. L. et al. Getting ready: Results of a randomized trial of a relationshipfocused intervention on the parent-infant relationship in rural Early Head Start. Infant Mental Health Journal, v. 33, n. 5, p. 439-458, 2012.

MCWILLIAM, R. A. Routines-based early intervention supporting young children and their families. Baltimore: Paul H. Brookes, 2010.

MCWILLIAM, R. A.; CASEY, A. M.; SIMS, J. The routines-based interview: A method for gathering information and assessing needs. Infants \& Young Children, v. 22, n. 3, p. 224-233, 2009.

MCWILLIAM, R. A. et al. The family-centeredness of individualized family services plans. Topics in Early Childhood Special Education,, v. 18, n. 2, p. 69-82, 1998.

ODOM, S. L.; BUYSSE, V.; SOUKAKOU, E. Inclusion for young children with disabilities: A quarter century of research perspectives. Journal of Early Intervention, v. 33, n. 4, p. 344-356, 2011.

ODOM, S. L. et al. Preschool inclusion in the United States: A review of research from an ecological systems perspective. Journal of Research in Special Educational Needs, v. 4, n. 1, p. 17-49, 2004.

ODOM, S. L.; WOLERY, M. A unified theory of practice in early intervention/ early childhood special education: Evidence-based practices. The Journal of Special Education, v. 37, n. 3, p. 164-173, 2003.

PETERSON, C. A. et al. Enhancing parent-child interactions through home visiting: Promising practice or unfulfilled promise? Journal of Early Intervention, v. 29, n. 2, p. 119-140, 2007.

RUSH, D. D.; SHELDEN, M. L.; HANFT, B. E. Coaching families and colleagues: A process of collaboration in natural settings. Infants \& Young Children, v. 16, n. 1, p. 33-47, 2003.

SALISBURY, C.; CAMBRAY-ENGSTROM, E.; WOODS, J. Providers' reported and actual use of coaching strategies in natural environments. Topics in Early Childhood Special Education, v. 32, n. 2, p. 88-98, 2012.

SALISBURY, C. L.; WOODS, J.; COPELAND. C. Provider perspectives on adopting and using collaborative consultations in natural environments. Topics in Early Childhood Special Education, v. 30, n. 3, p. 132-147, Nov. 2010.

SHELDEN, M. L.; RUSH, D. D. A primary-coach approach to teaming and supporting families in early childhood intervention. In: MCWILLIAM, R. A. (Ed.). Working with families of young children with special needs. New York: Guilford Press, 2010. p. 175-202. 
HUGHES-SCHOLES, C. H.; GAVIDIA-PAYNE, S. Development of a Routines-Based Early...

SUKKAR, H. Early childhood intervention: an Australian perspective. Infants and Young Children, v. 26, n. 2, p. 94-110, 2013.

Submitted: January 4, 2016. Approved: January 4, 2016. 